Original Research Paper

\title{
Enzymatic Kinetics of Fatty Acids Methyl Ester from Kapok Seed Oil (Ceiba Petandra) Using Lipozyme TL IM
}

\author{
Erin Ryantin Gunawan, Dedy Suhendra and Baiq Rizkia Miftahatul Hasanah \\ Department of Chemistry, Faculty Mathematics and Science, University of Mataram, Indonesia
}

\author{
Article history \\ Received: 04-09-2017 \\ Revised: 11-10-2017 \\ Accepted: 16-10-2017 \\ Corresponding Author: \\ Erin Ryantin Gunawan \\ Department of Chemistry, \\ Faculty Mathematics and \\ Science, University of \\ Mataram, Indonesia \\ E-mail: erinryantin@unram.ac.id
}

\begin{abstract}
Synthesis of Fatty Acids Methyl Ester (FAME) utilizing oil extracted from kapok seeds (Ceiba petandra) and catalyzed by lipozyme TL. 1M via enzymatic kinetics transesterification was succesfully conducted A mixture of different FAME, widely known as biodiesel is one of the sources of renewable energy. A kinetic analysis was investigated to identify the reaction model and the rate equation and to calculate kinetic parameters. The result obtained showed that the enzymatic kinetics followed a Michaelis-Menten model. The transesterification kinetic followed the Ping-pong $\mathrm{Bi}-\mathrm{Bi}$ mechanism characterized by the $v_{\max }, \mathrm{K}_{\mathrm{m}(\mathrm{KO})}, \mathrm{K}_{\mathrm{m} \text { (Met) }}$ values of $3.06 \times 10^{-5}$ $\mathrm{mmol} / \mathrm{min} . \mathrm{mg}$ catalyst, $0.95 \times 10^{2} \mathrm{ppm}, 1.30 \times 10^{2} \mathrm{ppm}$, respectively.
\end{abstract}

Keywords: Enzymatic, Kinetics, Fatty Acids Methyl Ester, Kapok Seed Oil

\section{Introduction}

FAME could be synthesized through transesterification using several substances, such as animal fats, waste cooking oils or animal fats. The process involving a glyceride and alcohol produces alcohol and fatty acid esters Physically, FAME properties and conventional dieseal are alike. FAME is also famous for its biodegradable and non-toxic nature properties. FAME is widely applied in the manufacture of bio-degradable materials, such as bio-lubricants, bio-fuels and bio-surfactants (Dossat et al., 2002; Shahla, 2012).

Some of the raw materials that have been successfully converted into FAME fromseed oil of canola, soybean,palm, sun flower and coconut (Achten et al., 2008). However, the raw materials are used as edible oil. One of the sources of non-edible materials that availability is abundant and can be converted into FAME is cotton seed oil. Previous studies showed that the oil content of kapok seed is $30.075 \%$, (Asnawati et al., 2014)

The synthesized FAME from the oils can be synthesized using chemicals and enzymatic catalyzed methods (Gunawan et al., 2011). The latter method is known to be expensive, however it provides advantages that the former cannot give. The advantage that captivates many researchers is the production of free fatty acids that does not cause saponification in the formed products. Other advantages that are well liked are its ability to produce optimum yield and preferable glycerol recovery. (Calabro et al., 2010).

In this work, the enzymatic transesterification of FAME from kapok seeds oil (Ceiba petandra) was performed using lipozyme TL. IM the employed lipase is from Thermomyces lanuginosus immobilized on silica gel. The enzim is six time less expensive compared to that of Lipozyme RM (Rhizomucor miehei) (Basri et al., 2013). Lipozyme RM IM is commonly used to catalyze the transesterification of oils (Gunawan et al., 2004; Awang and May, 2010). The aim of this research is to discover/establish the reaction rate of FAME production. This research imposes a significance contribution in designing a reactor to produce FAME in large quantities as the production process requires reaction kinetics data (Salamah, 2014).

\section{Materials and Methods}

Kapok seed oil, Immobilized lipase from Thermomyces lanuginosus produced by Novo Nordisk (Denmark) LA330045, Methanol 98\% was obtained from Fluka Chemika (Switzerland), Ester standards: methyl palmitate, methyl stearate, methyl oleate and methyl linoleate were purcashed from Sigma Aldrich (USA), Hexane was purchased from J.T. Baker (USA). All other chemicals were of analytical grade.

\section{Synthesis and Analysis}

Different amounts of enzyme were dissolved to $2 \mathrm{ml}$ $\mathrm{n}$-hexane, followed by molar ratios of substrate (oil and methanol). The mixture of Lipozyme TL IM., methanol and kapok seed oil were incubated in a horizontal water bath shaker $(120 \mathrm{rpm})$ at a various reaction time and at temperature of $40^{\circ} \mathrm{C}$. Gas chromatograph was used to 
analyse the mixture. RTx-65TG capillary column (30 $\mathrm{m} \times 0,25 \mathrm{~mm}$, Supelco, USA). Carrier gas employed was helium with flow rate $30 \mathrm{ml} / \mathrm{min}$. The runned temperature was $2 \mathrm{~min}$ at $40^{\circ} \mathrm{C}, 8^{\circ} \mathrm{C} / \mathrm{min}$ to $280^{\circ} \mathrm{C}$ and 5 min at $280^{\circ} \mathrm{C}$. Detector used was FID (Flame Ionization Detector) at $300^{\circ} \mathrm{C}$.

\section{Kinetic Enzymatic of FAME}

The initial rate of the reaction in the presence of different concentration of enzyme and variation of reaction time were studied. The amount of enzyme and reaction time used were 25 to $150 \mathrm{mg} \mathrm{Ml}^{-1}$ and 6 to $18 \mathrm{~h}$, respectively. Effect of Variation of molar ratio is 1; 0.5 to $0.1 ; 3.5 \mathrm{mmol}$ (oil; methanol) and the same ratio variation were applied to methanol; oil Water bath shaker (40C/120 rpm) was used to incubate the reaction mixture. Calculation of the initial rate of the reaction was obtained from from the graph of FAME formation against time. The unit of the slope generated from the graph was reported as $\mathrm{mmol} / \mathrm{min} . \mathrm{mg}$ catalyst. The maximum initial rate $\left(V_{\max }\right)$ and Michaels-Menten constanta $\left(K_{m}\right)$ was calculated using the Lineweaver-Burk plot.

\section{Result and Discussion}

\section{Effect of Enzyme Concentration of the Initial Rate}

Alcoholysis reaction was used to synthesize FAME using kapok seed oil, methanol and Lipozyme TL $1 \mathrm{M}$ as a catalysis. The Lipozyme was a lipase from Thermomyces lanuginosus. The effect of the amount of enzyme on the initial rate could be quantified to determine its catalytic effect. Regioselectivity of lipase plays an important role in specifying triglyceride molecule positions. This gives lipase a specificity properties.

Based on its selectivity, lipase could be categorized into acyl postion (regioselectivity) in the glycerol backbone (Chandler, 2001; Ghaly et al., 2010). There are three types of lipase, 1,3 specific, 2 specific, or non specific (Koskinen and Klibanov, 1996). Thermomyces lanuginosus wasthe type having a regioselectivity of 1.3 specific lipase (Robles-Medina et al., 2009; Ghaly et al., 2010).

Figure 1 showed the relationships between theinitial rate of the transesterification of kapok seed oil at different enzyme concentration (25-150 $\left.\mathrm{mg} \mathrm{L}^{-1}\right)$ and fixed substrate concentrations. It was found that when the concentration of enzyme rise $\left(25-50 \mathrm{mg} \mathrm{L}^{-1}\right)$, the initial rate increased. This was due to the lipase enzymes that acted as catalyst. The calculated optimum initial rate was $7.412 \times 10^{-4} \mathrm{mmol} / \mathrm{min}$. The presence of the catalyst reduced the activation energy in order to accelerate the occurrence of a reaction. The enzymes were capable to converte fatty acids into FAME completely. However, when the enzyme concentration was 75 to $150 \mathrm{mg} \mathrm{mL}^{-1}$, the initial rate of the reaction decreased and inclined stable, at $4.4 \times 10^{-4} \mathrm{mmol} / \mathrm{min}$. The amount of the enzyme was a significant factor determining the rate and efficiency of the reaction (Manurung et al., 2014) Unfortunately, at times, the increase of lipase concentration did not result in higher conversion due to the inhibitor presence. Another reason was because the immobilized enzymes working as the catalyst could no longer react with the substrate, thus preventing the increase of the initial rate of the reaction

\section{Effect of Reaction Time}

Figure 2 reveals time course of the enzymatic transesterification Fig. 2 reveals time course of the enzymatic transesterification which could be used as a reference of "enzyme performance and reaction progress It is also an indicator to determine adequate or shortest time needed to achieve expected results, for instance less production expenses and good yields (Yee et al. 1997). The percentage yield of FAME showed an increase up to $10 \mathrm{~h}$ reaching $80.07 \%$ but slightly decreased when it hit 20 $\mathrm{h}$. Reduction of the percentage yield (above $10 \mathrm{~h}$ Occurred due to the increase of glycerol to lipase concentration. This limited the surface area contact between the substrate and Lipozyme TL.IM (Basri et al.., 2013).

\section{Study of Enzyme Kinetics}

Enzyme as a catalyst is one of the attractive areas of study in chemical kinetics. Kinetics study of transesterification of FAME using lipozyme TL. IM. was best achieved by measuring the initial rate in the presence of different substrate concentrations. In enzyme kinetics, it was customary to measure the initial rate of a reaction to minimize reversible reactions and the inhibition of enzymes by products (kinetic book). Figure 3 depicts the relationship of initial rate of transesterification of kapok seed oil in different oil substrate initial concentration (1$3.5 \mathrm{mmol}$ ) and fixed methanol concentration.

As observed, the initial rate of the reaction increased with the increase of Methanol (M) concentration and reached the maximum rate at the concentration of 3.5 mmol of Kapok seed Oil (KO)

A similar trend was also found on the use of different kapok seed oil cencentration, where the initial rate of the reaction was also dependent on the methanol concentration.

The presence of enzyme catalysis cause a dramatic increase of the reaction rate and increase high specivity.

In this case, the process involved two substrates. However, the enzymatic catalysis of the two substrates could be controlling concentration of one of the substrates. This results in the formation of a plot following Michelis-Menten relationship between the initial rate and the other substrate concentration (Lai et al., 1999). Michaelis and Menten provided an explanation regarding a mechanism of "the initial rate of enzyme-catalyzed reactions" that is highly affected by the concentration. The Curve as shown in Fig. 3 and Fig. 4 was a hyperbolic shape. The hyperbolic indicated that the reactions followed Michaelis-Menten type (Awang et al., 2004; Gonze and Kaufman, 2016). 


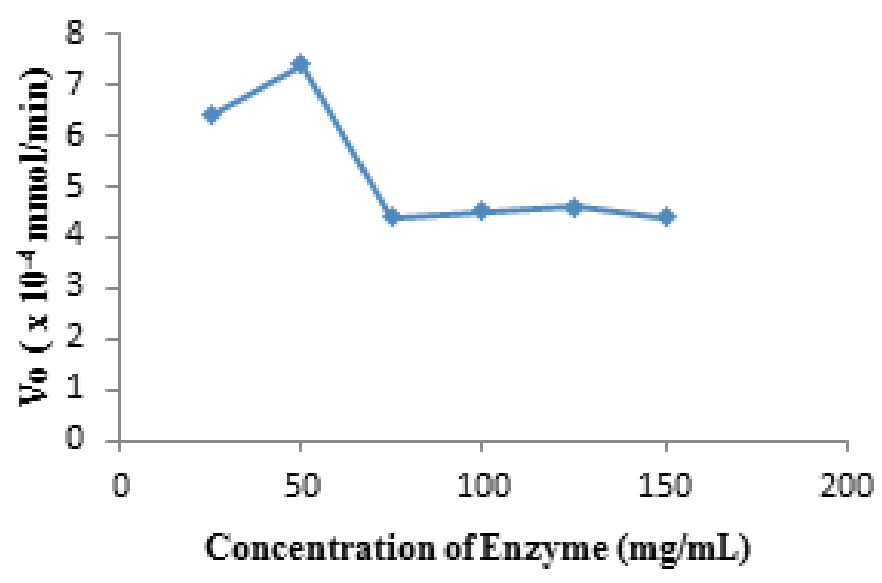

Fig.1. Effect of Enzyme Concentration on the Initial Rate

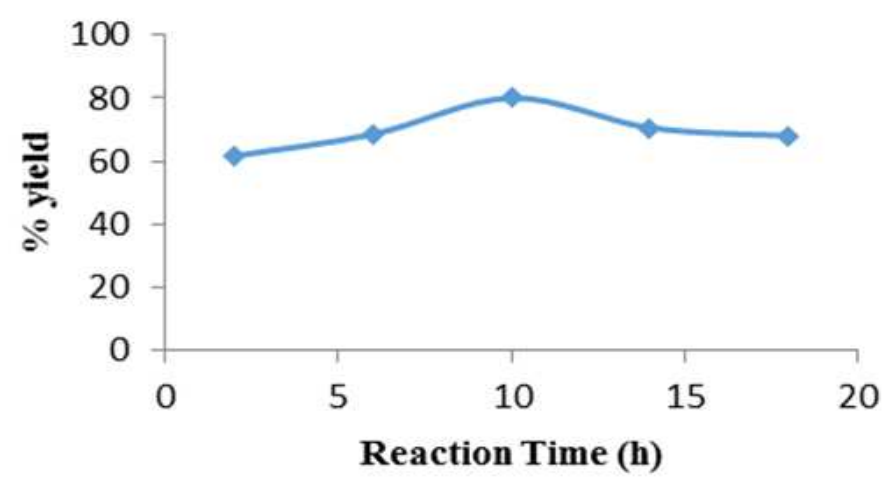

Fig. 2. Effect of reaction time

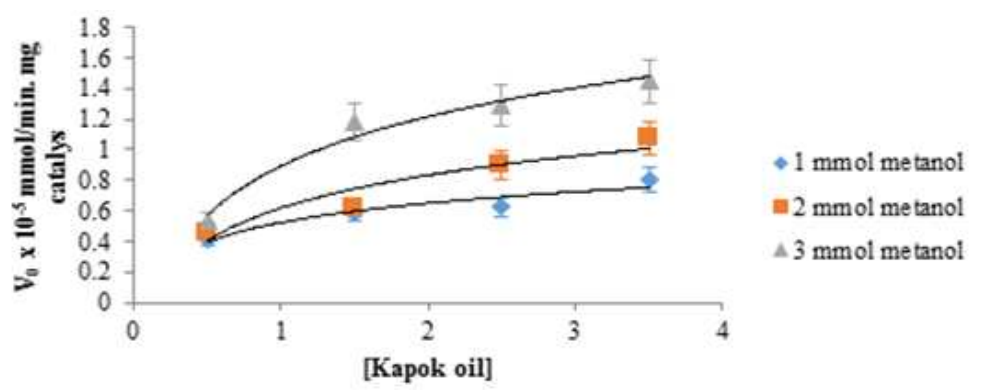

Fig. 3. Initial reaction rate of transesterification as a function of kapok seed oil concentration

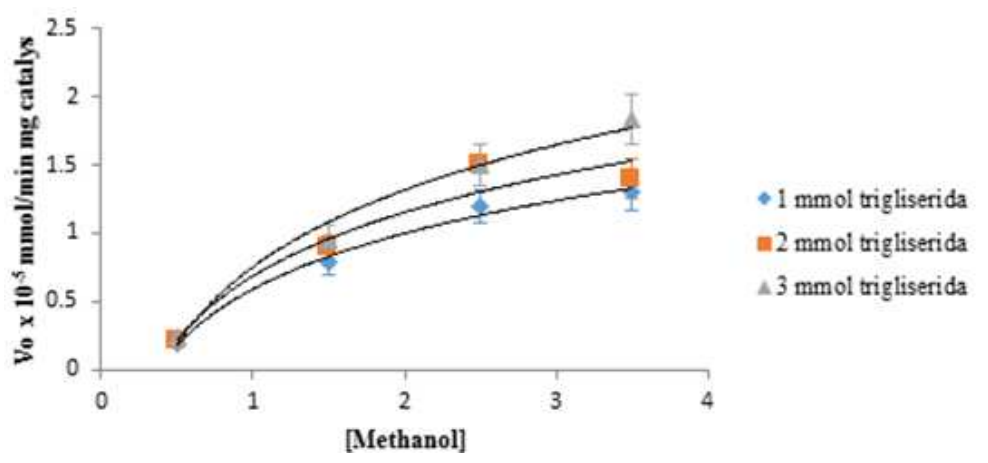

Fig. 4. Initial reaction rate of transesterification as a function of methanol concentration 
In an enzymatic reaction, the presence of substrates or other products should be observed as they could act as inhibitors (Romero et al., 2007). In this research, alcohol did not show any inhibition activities. The rate equation for this reaction with assumtion no inhibition from both substrates and products was given by Segel (1975) and Romero et al. (2007)

$$
v=\frac{v_{\max }[\mathrm{KO}][\mathrm{Met}]}{K_{M(\mathrm{KO})}[\mathrm{Met}]+K_{M(\operatorname{met})}[\mathrm{KO}]+[\mathrm{KO}][\mathrm{Met}]}
$$

where, $v_{\max }$ is the maximum reaction rate, $v$ is the initial reaction rate and $K_{M(K O)}$ and $K_{M(m e t)}$ are the binding constants (Michaelis constants) for both substrates, Kapok Oil (KO) and Methanol (Met). This equation can be modified to linear regression equation.

$\frac{1}{v}=\frac{K_{M(K O)}[\mathrm{Met}]+K_{M(\operatorname{met})}[\mathrm{KO}]+[\mathrm{KO}][\mathrm{Met}]}{v_{\max }[\mathrm{KO}][\mathrm{Met}]}$

$\frac{1}{v}=\frac{K_{M(K O)}}{v_{\max }[K O]}+\frac{K_{M}(m e t)}{v_{\max }[M e t]}+\frac{1}{v_{\max }}$

For constant methanol concentrations, equation shown below:

$$
\frac{1}{v}=\frac{K_{M(K O)}}{v_{\max }[K O]}+\frac{1}{v_{\max }}
$$

And for constant kapok oil concentrations, equation shown below:

$$
\frac{1}{v}=\frac{K_{M(m e t)}}{v_{\max }[M e t]}+\frac{1}{v_{\max }}
$$

Figure 5 shows a relationship between the initial rate and concentration of double reciprocal kapok oil at several methanol concentrations. The plot formed follows the double reciprocal line weaver bulk plot, It can be further used to generate the dependency of the intercept values At varied concentrations of methanol to yield the values of $K_{M}$ for slope and $v_{\max }$ for intercept. The values of kinetics constant were shown in Table 1.
The other experiments for reciprocal methanol concentration at several kapok oil concentration were shown in Scheme 1. The experiment with varied kapok oil and methanol concentration. Exhibited that there was a linear correlation between initial reaction rate and substrate concentration studied, in which the initial rate went up when the substrate concentration raised increasd on the linear line as shown in Fig. 6.

The parallel line indicated the reaction mechanism of kapok oil and methanol via enzymatic transesterification followed a Ping-pong Bi-Bi mechanism. The analysis results was used to model the Ping Pong Bi-Bi model and the sequence of the reaction is presented below:

Based on the calculated kinetics parameters (Table 1), it was found Enzyme's affinity leaned more to kapok oil compared to that of methanol since $K_{m(K O)}$ was lower than $K_{m(M e t) . .}$ Romero et al. (2007) reported that in their research that the affinity of enzyme towards the substrate was inversely propotional with the value of MichaelisMenten constant.

Previous studies have laid a foundation used to understand mechanism of FAME production following a Ping Pong model (Azocar et al., 2014; Al-Zuhair et al., 2007). The proposed mechanism considered that FAME was mainly produced through transesterification pathway. In Fig. 5 and Fig. 6, it could be observed that the $\mathrm{R}^{2}$ coefficient of determination of kapok oil and methanol concentration was 0.9897 and 0.9910 respectively. These result indicated that proposed quite well with the experimental data. Similar results were found in Basri et al. (2013) and Bhandari et al., (2013) studies.

Scheme 2 showed the Enzyme (E) transesterification mechanism for kapok oil enzyme-complex (E-KO) and an acylated enzyme fatty acid complex (E-Ac-G). Glycerol was released as the first product. Afterward, the complex reacted with methanol forming complex an acylated enzyme-methanol (E-Ac-Met). The complex then went through an esterification reaction forming an ester-enzyme complex. The free Enzyme (E) the free enzyme will be regenerated as a second product due to the release of FAME.

Table 1. Kinetics parameter for transesterification of kapok oil and methanol using Lipozyme TL IM

\begin{tabular}{lll}
\hline Parameter & Units & Value \\
\hline$v_{\max }$ & $\mathrm{mmol} / \mathrm{min} . \mathrm{mg}$ catalyst & $3.06 \times 10^{-5}$ \\
$K_{\max (\mathrm{KO})}$ & $\mathrm{ppm}$ & $0.95 \times 10^{2}$ \\
$K_{\max (\mathrm{Met})}$ & $\mathrm{ppm}$ & $1.30 \times 10^{2}$ \\
\hline
\end{tabular}

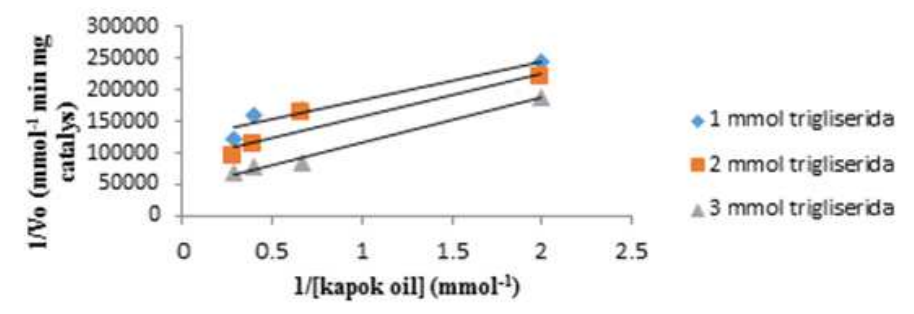

Fig. 5. Line weaver-Burk plots of kapok oil concentration vs initial rate of reaction 


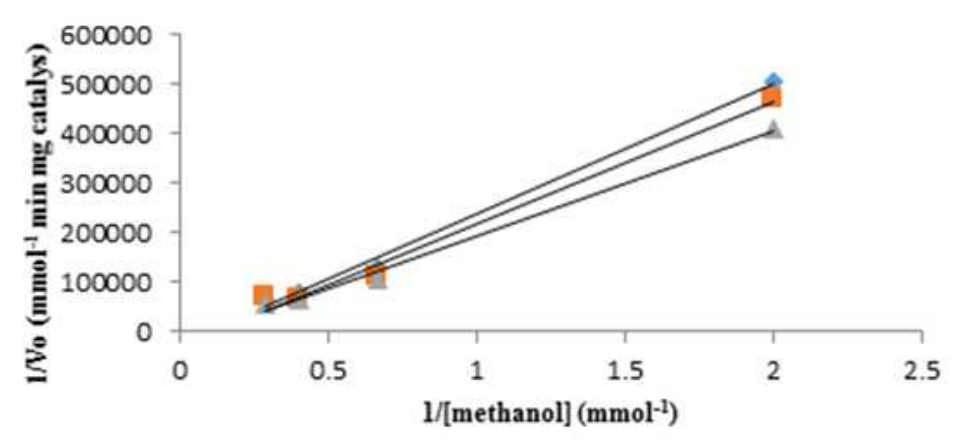

Fig. 6. Line weaver-Burk plots of methanol concentration vs initial rate of reaction

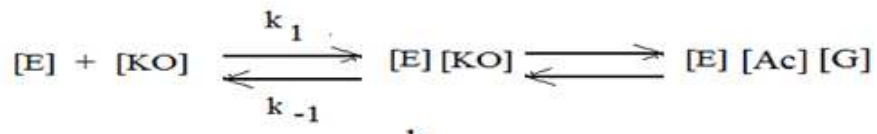

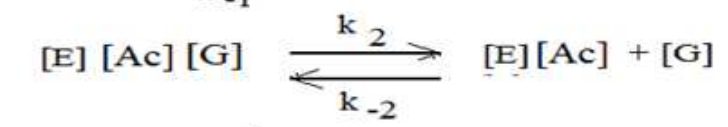

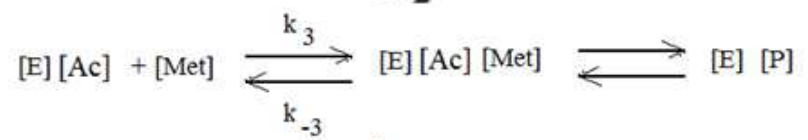

$$
\begin{aligned}
& \text { [E] [P] } \underset{\mathrm{k}_{-4}}{\stackrel{\mathrm{k}_{4}}{\rightleftarrows}}[\mathrm{E}]+[\mathrm{P}]
\end{aligned}
$$

Scheme 1. The Process of Enzymatic reactions, $[\mathrm{KO}]$ is kapok oil, [Met] is methanol, $[\mathrm{E}]$ is enzyme, $[\mathrm{G}]=$ glycerol, $[\mathrm{P}]=$ =product, $[\mathrm{Ac}]=$ acylated, $\mathrm{k}=$ rate constanta

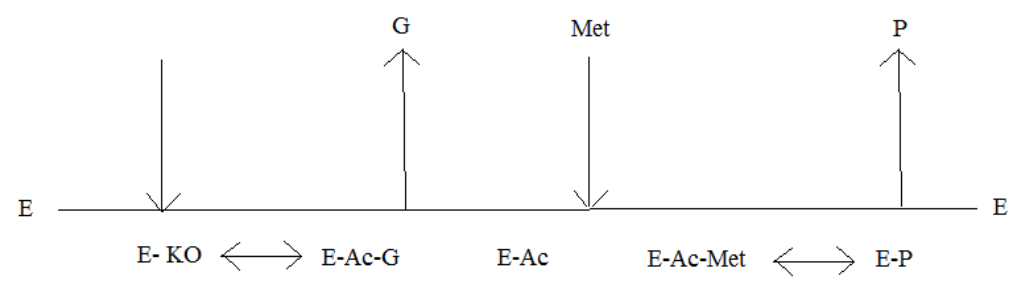

Scheme 2. Ping-pong Bi-bi transesterification mechanism of FAME production

A bi-bi Ping-Pong mechanism was also hypothesized to describe the kinetics of enzymatic trans-esterification of glycerides for biodiesel production from triolein and ethanol (Calabro et al., 2010).

\section{Conclusion}

The kapok seed oil transesterification reaction kinetics with ethanol and Lipozyme TL. 1M was established. The study results showed that the mechanism of the reaction followed the Bi-Bi Ping-Pong mechanism with the absence of inhibition under a concentration of 3,5 mmol for both (Kapok seed oil and methanol) and it followed a-Michaels-Menten kinetics. The affinity of the enzyme leaned more to kapok oil compared to that of methanol because $\mathrm{Km}$ (KO) was lower than $K m$ (Met). A parallel line on the graph and the value of $\mathrm{R}^{2}$ ranging from $0.9897-0.9910$ showed that the models of bi-bi Ping-pong was suitable for this reaction.

\section{Acknowledgement}

I wish to acknowledge the Directorate General of Research and Development Strengthening, The Ministry of Research Technology and Higher Education Republic of Indonesia.

\section{Author's Contributions}

Erin Ryantin Gunawan: Participated in all experiments, organized the study and contributed to the writing of the manuscript 
Dedy Suhendra: Designed the research plan and coordinated the data-analysis and contributed to the writing of the manuscript

Baiq Rizkia Miftahatul Hasanah: Participated in all experiments and assisted data analysis

\section{Ethics}

This article has not been published before and the data listed are in accordance with the results of our team's research. We ensure there is no ethical involvement

\section{References}

Achten, W.M.J., L. Verchot, Y.J. Franken, E. Mathijs and V.P. Singh ET AL., 2008. Jatropha bio-diesel production and use. J. Biomass Bioenergy, 32: 1063-1084.

Al-Zuhair, S., F.W. Ling and L. S. Jun, 2007. Proposed kinetic mechanism of the production of biodiesel from palm oil using lipase. Process. Biochem., 42: 951-960.

Asnawati, D., E.R., Gunawan and A.S. Ridhani, 2014, The synthesis of biodiesel from kapak seed oil (Ceiba Pentandra) through enzymatic transesterification. Media Bina Ilmiah, 8: 1-11.

Awang, R. and C.Y. May, 2010, Enzymatic Synthesis of Palm Alkyl Ester Using Dialkyl Carbonate as an Alkyl Donors, Am. J. Appl. Sci. 7: 8 (1083-1086)

Awang, R., M. Basri S. Ahmad and A.B. Salleh, 2004. Lipase-catalyzed esterification of palm-based 9, 10-dihydroxystearic acid and 1-octanol in hexane a kinetic study. Biotechnol. Lett., 26: 11-14.

Azocar, L., R. Navia, L. Beroiz, D. Jeison and G. Ciudad, 2014. Enzymatic biodiesel production kinetics using co-solvent and an anhydrous medium: a strategi to improve lipase performance in a semicontinous reactor. New Biotechnol., 13: 422-429.

Basri, M., M.A. Kassim, R. Mohamad and A.B. Ariff, 2013, Optimization and kinetic study on the synthesis of palmoil ester using lipozyme Tl Im. J. Mol. Catal. B Enzym, 85-86: 214-219 .

Bhandari, K., S.P. Chaurasia, A.K. Dalai, A. Gupta and K. Singh, 2013, Kinetic Study on enzymatic esterification of tuna fish oil fatty acids with butanol, J. Mol. Catal. B:Enzym, 94 : 104-110

Calabro, V., E. Ricca, M.G. De Paola, G. Iorio and S. Curcio, 2010. Kinetics of enzymatic transesterification of glycerides for biodiesel production. Bioprocess Biosyst. Eng., 33: 701-710. DOI: $10.1007 / \mathrm{s} 00449-009-0392-\mathrm{Z}$

Chandler, I.C., 2001. Determining the regioselectivity of immobilized lipases in triacylglycerol acidolysis reactions. J. Am. Oil Chem. Soc., 78: 737-742. DOI: $10.1007 / \mathrm{s} 11746-001-0335-7$
Dossat, V., D. Combes and A. Marty, 2002. Lipasecatalysed transesterification of high oleic sunflower oil, Enz. Microb. Technol. 30: 90-94.

Ghaly, A.E., D. Dave, M.S. Brooks and S. Budge, 2010. Production of biodiesel by enzymatic transesterification: Review. Am. J. Biochem. Biotechnol., 6: 54-76.

Gonze, D. and M. Kaufman, 2016. Chemical and enzyme kinetics.

Gunawan, E.R., M. Basri and D. Suhendra, 2011, Enzyme-catalysed synthesis of palm-based wax esters-a kinetic study. J. Natur. Indonesia, 14: 37-41.

Gunawan, E.R., M. Basri, M.B.A. Rahman, A.B. Saleh and R.N.Z.A. Rahman, 2004. Lipase-catalyzed synthesis of palm-based wax esters. J. Oleo Sci., 53: 471-477.

Koskinen and Klibanov, 1996. Enzymatic reaction in organic media.

Lai, D.T., N. Hattori and C.J. O’Connor, 1999. Kinetics of enzymatic synthesis of isopropylidene glycerol esters by goat pregastric lipase. J. Am. Oil Chem. Soc., 76: 845-851.

Manurung, R., M. Widyawati and R. Afrianto, 2014. The synthesis biodiesel from palm oil through interesterification using imobilized lipase enzym as catalyst. Internat. J. Sci. Eng., 7: 174-177

Robles-Medina, A., P.A. Gonzalez-Moreno, L. EstebanCerdán and E. Molina-Grima, 2009. Biocatalysis: Towards ever greener biodiesel production. Biotechnol. Adv., 27: 398-408. DOI: $10.1016 /$ j.biotechadv.2008.10.008

Romero, M.D., L. Calvo, C. Alba and A. Daneshfar, 2007. A kinetic study of isoamyl acetate synthesis by immobilized lipase-catalyzed acetylation in $n$ hexane. J. Biotechnol., 127: 269-277.

Salamah, S., 2014. The kinetics of the esterification reaction kapok seed oil in biodiesel production. Chemica, 1: 11-18.

Segel, H., 1975. Enzyme Kinetics: Behaviour and Analysis of Rapid Equilibrium and Steady-state Enzyme Systems. 1st Edn., John Wiley and Sons, Inc., New York.

Shahla, S., G.C. Ngoh and R. Yusoff, 2012. The evaluation of various kinetic models for basecatalyzed ethanolysis of palm oil. Bioresour. Technol., 104: 1-5.

Yee, L.N., C.C. Akoh and R.S. Philips, 1997. Lipase PScatalyzed transesterification of citronellyl butyrate and geranyl caproate: Effect of reaction parameters. J. Am. Oil Chem. Soc., 74: 255-259. 